\title{
Comida y lingüística hispánica (siglos XVI-XIX) “e dintorni”
}

\author{
Food and Hispanic linguistics (16th-19th centuries) "e dintorni"
}

\author{
Nancy De BenedetTo \\ alfonsina.debenedetto@uniba.it \\ Università degli Studi di Bari
}

La comida y la gastronomía constituyen un ámbito lingüístico especial muy extenso y vario que cuenta con excelentes repertorios de estudios que, sobre todo a partir de los años ochenta del siglo pasado, han sacado a luz textos y han ido también acumulando distintas reflexiones críticas en muchos casos exhaustivas y de gran calidad. A pesar de ello, todavía quedan por profundizar muchos aspectos y enteras perspectivas del cruce entre comida y lingüística por estudiar. Precisamente, el presente monográfico representa un primer acercamiento a unas líneas de investigación que estamos esbozando entre diversos estudiosos italianos. Desde una perspectiva diácrónica se abre una trayectoria muy larga, así como, a nivel de contenidos, se presentan unos variados nucleos de intereses. De hecho, por un lado se entrecruzan lingüística y filología ya que nos volvemos a encontrar con las promiscuas ocupaciones de Aldonza Lorenzo y su magnífica cocina sin manteca de cerdo (Perugini); se añaden sutiles reflexiones a las relaciones entre el Banquete de nobles caballeros y el Vergel de Sanidad de Luis Lobera de Ávila (Baldissera) y hacemos hincapié en libros complicados, como el recetario de Diego Granado de 1599, que todavía queda a la espera de un laborioso estudio crítico (De Benedetto). Por el otro, se exponen los primeros resultados del grupo de Verona / Pisa que trabajan básicamente sobre tres ámbitos de investigación: la constitución de un corpus 
de textos del siglo XIX que comprende recetarios, tratados y glosarios gatronómicos (Dalle Pezze - Sartor); el análisis lexicográfico de las voces recogidas por los diccionarios académicos y no académicos con especial atención a los del siglo XVIII y XIX (Carpi - De Beni); y, por último, el análisis de traducciones entre Italia y España (Pérez - Aguilar Domingo).

Más allá del área europea, y siempre desde una perspectiva diacrónica, se presentan un estudio que se enfrenta con la sedimentación del léxico de la alimentación en los diccionarios fundacionales chilenos (Chávez Fajardo) y un interesante recorrido por las tradiciones alimentarias argentinas para delinear su relación con la naciente identidad nacional, en textos literarios publicados a caballo entre los siglos XIX y XX (Magnani). Así mismo, con vistas a la contemporaneidad, se analiza la presencia del léxico específico de manera contrastiva en los diccionarios bilingües italiano/español (Ariolfo). 